\title{
Resistance Determinants and Their Association with Different Transposons in the Antibiotic-Resistant Streptococcus pneumoniae
}

\author{
Izabela Korona-Glowniak, Radoslaw Siwiec, and Anna Malm \\ Department of Pharmaceutical Microbiology, Medical University of Lublin, Chodzki 1, 20-093 Lublin, Poland \\ Correspondence should be addressed to Izabela Korona-Glowniak; iza.glowniak@umlub.pl
}

Received 22 December 2014; Revised 16 March 2015; Accepted 16 March 2015

Academic Editor: Henny C. van der Mei

Copyright (c) 2015 Izabela Korona-Glowniak et al. This is an open access article distributed under the Creative Commons Attribution License, which permits unrestricted use, distribution, and reproduction in any medium, provided the original work is properly cited.

\begin{abstract}
Multiple resistance of Streptococcus pneumoniae is generally associated with their unique recombination-mediated genetic plasticity and possessing the mobile genetic elements. The aim of our study was to detect antibiotic resistance determinants and conjugative transposons in 138 antibiotic-resistant pneumococcal strains isolated from nasopharynx of healthy young children from Lublin, Poland. These strains resistant to tetracycline and/or to chloramphenicol/erythromycin/clindamycin were tested by PCR using the specific genes as markers. The presence of Tn916 family transposons, carrying tet $(\mathrm{M})$ and int/xis $\mathrm{Tn} 916$, was observed in all of the tested strains. Tn916 was detected in 16 strains resistant only to tetracycline. Tn 6002 and $\operatorname{Tn} 3872$-related element were found among $99 \mathrm{erm}(\mathrm{B})$-carrying strains (83.8\% and 3.0\%, resp.). Eight strains harbouring mef(E) and erm(B) genes were detected, suggesting the presence of Tn2010 and Tn2017 transposons. Among 101 chloramphenicol-resistant strains, two variants of Tn5252-related transposon were distinguished depending on the presence of int/xis5252 genes specific for cat gene-containing Tn5252 (75.2\% of

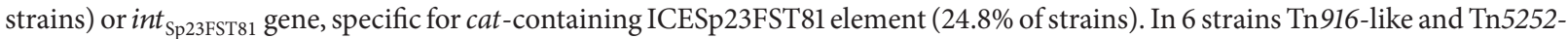
like elements formed a Tn5253-like structure. Besides clonal dissemination of resistant strains of pneumococci in the population, horizontal transfer of conjugative transposons is an important factor of the high prevalence of antibiotic resistance.
\end{abstract}

\section{Introduction}

Antimicrobial resistance among Streptococcus pneumoniae has spread worldwide and it causes higher risk of treatment failure in pneumococcal infections. S. pneumoniae is an important human pathogen associated with respiratory tract infections, bacteriemia, and meningitis. Primarily as a commensal, the pneumococcus colonizes the nasopharynx of $10-20 \%$ of healthy adults and $40-77 \%$ of healthy children [1] . Nasopharyngeal carriage in healthy children is a major factor in the horizontal transmission of pneumococcal strains, especially between children attending day care centers (DCCs) or to other family members, and may be also the source of infection in other individuals. Moreover, pneumococcal nasopharyngeal isolates reflect the strains currently circulating in the community $[1,2]$.
Multiple resistance of pneumococci especially resistance to macrolides and tetracyclines as well as to chloramphenicol is generally associated with their unique recombinationmediated genetic plasticity and possessing the mobile genetic elements $[3,4]$. Two major mechanisms of macrolide resistance in S. pneumoniae are noted. The first one is target site modification by a ribosome methylase, encoded by $\operatorname{erm}(B)$ gene and related to high-level resistance to macrolide, lincosamides, and streptogramin B (MLS $\mathrm{B}_{\mathrm{B}}$ phenotype). $\operatorname{Erm}(\mathrm{B})$ resistance can be expressed by pneumococci either constitutively $\left(\mathrm{CMLS}_{\mathrm{B}}\right.$ phenotype) or inducibly (iMLS $\mathrm{B}_{\mathrm{B}}$ phenotype) [5]. The majority of macrolide-resistant $S$. pneumoniae strains are also resistant to tetracycline. This association is due to the insertion of erm(B) into conjugative and composite transposons of the Tn916 family that harbours tet $(M)$ gene, encoding ribosome protection proteins. Members of this 
family, which carry erm(B), include Tn6002, Tn1545 (which also carries the kanamycin resistance gene aph3-III), and $\operatorname{Tn} 3872$ (which also carries transposase genes tnpA and $\operatorname{tnpR}$ ) [6-9].

The second macrolide resistance mechanism is an efflux pump (encoded by mef genes) which confers resistance to 14- and 15-member macrolides only ( $\mathrm{M}$ phenotype). The two main subclasses of mef gene in pneumococci are carried on different but related elements: $m e f(\mathrm{~A})$ on the defective transposons $\operatorname{Tn} 1207.1$ or $\operatorname{Tn} 1207.3$ [10] and $m e f(E)$ on a MEGA element (macrolide efflux genetic assembly) [11]. The prevalence of isolates carrying both mef and erm(B) has reportedly increased. Recently two new composite elements of the Tn916 family, containing tet(M) plus MEGA (Tn2009) and tet(M), erm(B), and MEGA (Tn2010) have been described [9, 12-15].

Resistance to chloramphenicol in S. pneumoniae is due to acetylation of the antibiotic by chloramphenicol acetyltransferase (CAT), encoded by cat gene, which is carried on the Tn5253-like, a composite structure made up of two independent conjugative transposons, when Tn916-like tet(M)carrying element designated Tn5251 was inserted within the Tn5252 element that carries chloramphenicol resistance [1618 .

The distribution of pneumococcal transposons and genes they harbour varies in different geographic regions. There are scanty data as far as distribution of conjugation transposons in Poland is concerned. The aim of our study was to detect antibiotic resistance determinants and conjugative transposons in the antibiotic-resistant pneumococcal strains isolated from nasopharynx of healthy children aged 3-5 attending day care centres in Lublin, Poland.

\section{Materials and Methods}

2.1. Bacterial Strains. A total of 138 strains were selected from the previously described collection of 342 isolates obtained from nasopharynx of healthy 311 children aged 3 to 5 attending day care centres in Lublin, Poland [19]. The inclusion criteria were phenotype of resistance to one or more of tetracycline, chloramphenicol, erythromycin, and clindamycin.

\subsection{Determination of the Macrolide Resistance Phenotype.} The tested strains were assigned to the constitutive (cMLS), the partially inducible (iMcLS), the inducible (iMLS), or the efflux-mediated (M) macrolide resistance phenotype on the basis of the triple-disk (erythromycin plus clindamycin and rokitamycin) test, as described previously [5].

2.3. Amplification Experiments and Gene Detection. Bacterial genomic DNAs were prepared with Genomic Mini Kit (A\&A Biotechnology, Gdynia, Poland) and were used as templates for PCR. Macrolide resistance genes erm(B) and $m e f A / E$ were detected by PCR using the primers and conditions described previously [20]. The PCR product of the $m e f A / E$ gene was digested with BamHI (Fermentas) to differentiate between the $m e f(\mathrm{~A})$ and $m e f(\mathrm{E})$ gene subclasses
[21]. PCR amplification was used to detect $c_{p C 194}$ gene related to chloramphenicol resistance [22]. The Tn916 and Tn917 transposon-related genes (int916, xis916, tnpA, and $\operatorname{tn} p R$, O13-O14), the tetracycline resistance gene, tet $(\mathrm{M})$, and the promoter of the aph3-III gene were detected by PCR using the primers and conditions described previously $[23,24]$. PCR with primer pair J12/J11 which amplified the region orf20 to orf19 was used to distinguish among $\operatorname{Tn} 3872$, Tn6002, and Tn6003/Tn1545, which yield amplicons of $0.8 \mathrm{~kb}$, $3.7 \mathrm{~kb}$, and $7.9 \mathrm{~kb}$, respectively [23]. An erm(B)/tet (M) linkage was detected using the primers described previously [23]. The mef(E)-positive isolates were analyzed for the presence of Tn2009-like element by PCR with primers MEF4 and O14 [13, 25]. REDTaq ReadyMix (Sigma-Aldrich) was used in standard PCR and Long PCR Enzyme Mix (ThermoScientific) was used in reaction expected to yield PCR products exceeding $3 \mathrm{~kb}$ in size.

The resistance gene combination related to the different presumed transposons was Tn6002 $(\operatorname{erm}(\mathrm{B}), \operatorname{tet}(\mathrm{M})$, int 916 , xis916, and O13-O14), Tn3872 (erm(B), tet(M), tnpA, tnpR, int916, and xis916), Tn6003 or Tn1545 (erm(B), tet(M), int916, xis916, and aph3-III), Tn2010 (erm(B), tet(M), int916, xis916, mef(E), and MEF4-O14), and Tn2017 (erm(B), tet(M), int916, xis916, mef(E), MEF4-O14, tnpA and tnpR). Tn5252 was detected by PCR of its transposase gene, int5252, and excisionase xis5252 [26]. For the detection of Tn5253, the region of the right junction between Tn5251 and Tn5252 was analyzed [27]. Primers for the detection of ICESp23FST81 have been described elsewhere [26].

\section{Results}

The 138 pneumococcal isolates were characterized for genotypic attributes. Serotyping and antibiotic resistance patterns of these strains were determined previously [19]. Among the tested strains, 77 (55.8\%), 35 (25.4\%), 23 (18.0\%), 2 (1.4\%), and $1(0.7 \%)$ belonged to serotypes 19F, 6B, 23F, 23A, and 14 , respectively (Table 1 ). All of the strains were resistant to tetracycline (Te) but showed various resistance to other antimicrobials. A total of $71.7 \%$ strains were additionally resistant to erythromycin (E) and clindamycin (Cc) while $73.9 \%$ strains were resistant to chloramphenicol (C) as well. On the basis of the erythromycin-clindamycin-rokitamycin triple-disk test, 82 of the 99 strains resistant to erythromycin and clindamycin were assigned to the cMLS phenotype, 17 were assigned to the iMcLS phenotype, and none was assigned to the iMLS phenotype or to the M phenotype. All strains with iMcLS phenotype belonged to 6B serotype.

3.1. Detection of Resistance Genes. All of the strains possessed the tet $(\mathrm{M})$ gene. All cMLS and iMcLS isolates had the erm(B) gene. The $m e f(\mathrm{E})$ gene, but not $m e f(\mathrm{~A})$, was also found in 8 isolates with the erm(B) gene: 1 of the iMcLS phenotype and 7 of the cMLS phenotype. None of the strains, positive for the promoter of the aph3-III gene, were found. Each of the strains with resistance to chloramphenicol was positive for the cat $_{p \mathrm{C} 194}$ gene. 
TABLE 1: Resistance patterns and serotypes of 138 S. pneumoniae nasopharyngeal isolates from healthy young children.

\begin{tabular}{lc}
\hline Resistance pattern & Serotypes (number of strains) \\
\hline $\mathrm{Te}$ & $23 \mathrm{~F}(16)$ \\
$\mathrm{TeC}$ & $19 \mathrm{~F}(22), 23 \mathrm{~F}(1)$ \\
$\mathrm{ECcTe}$ & $6 \mathrm{~B}(13), 14(1), 19 \mathrm{~F}(2), 23 \mathrm{~F}(5)$ \\
$\mathrm{ECcTeC}$ & $6 \mathrm{~B}(22), 19 \mathrm{~F}(53), 23 \mathrm{~A}(2), 23 \mathrm{~F}(1)$ \\
\hline
\end{tabular}

E: erythromycin, Cc: clindamycin, Te: tetracycline, and C: chloramphenicol.

3.2. Transposon Distribution. Table 2 shows the PCR detection of the relevant genetic determinants of resistance genes and transposons. All of the tested strains were positive for the genes coded integrase and excisionase Tn916, which indicated presence of elements of the Tn916 family. For the further analysis of the tet $(\mathrm{M})$-carrying transposons, the strains were split into four phenotypic groups with respect to their resistance patterns, namely, $\mathrm{Te}, \mathrm{TeC}, \mathrm{ECcTe}$, and ECcTeC. Among 16 Te isolates, in addition to integrase and excisionase genes, the PCR product of O13-O14 fragment was positive, which indicated an intact structure of the Tn916-like transposons behind the tet $(\mathrm{M})$ gene (orf9) [25]. The size of orf20-orf19 amplicon obtained in this group of strains was $0.8 \mathrm{~kb}$. Seventeen isolates out of ECcTe group and 66 isolates out of ECcTeC group most probably carried the Tn6002 transposon, as suggested by the positive O13O14 PCR result, amplification of the erm(B) gene, and its connection with tet $(\mathrm{M})$ gene as well as the size of orf20-orf19 amplicon $(3.6 \mathrm{~kb})$. Additionally, 4 of ECcTeC isolates and 4 of ECcTe isolates were positive in amplification of the mef gene. MEGA element included in Tn6002, creating Tn2010, was suspected in 7 of them, as suggested by the positive PCR fragment with primers MEF4 and O14, and the last one was positive in $\operatorname{Tn} 917$ genes $(\operatorname{tnp} \mathrm{A} / \operatorname{tn} p \mathrm{R})$ and negative in O13-O14 PCR product, suggesting Tn2017 element. The vast majority of the 78 isolates from $\mathrm{ECcTeC}$ group produced in PCR the amplicons of integrase and excisionase genes specific for the cat gene-containing Tn5252. In six ECcTeC strains the Tn916-like and the Tn5252-like elements formed a Tn5253-like structure, as revealed by PCR product of the junction region [16]. Two of $\mathrm{ECcTeC}$ strains were found to contain the Tn3872-like transposon, being positive by the PCR products for $\operatorname{tn} p \mathrm{~A}+\operatorname{tn} p \mathrm{R}$ and linkage between tet $(\mathrm{M})$ and $\operatorname{erm}(\mathrm{B})$. Orf20-orf19 amplicon obtained from this group of strains was found to be $0.8 \mathrm{~kb}$ in size. Two isolates from $\mathrm{ECcTeC}$ group and 23 isolates of the $\mathrm{TeC}$ group were negative in integrase and excisionase specific for Tn5252, but these isolates possessed transposase specific for cat-containing ICESp23FST81 element.

Figure 1 shows the distribution of presumable transposons among serotypes of the tested strains.

\section{Discussion}

Antibiotic resistance in S. pneumoniae is often carried by the mobile genetic elements that reside in the chromosome, such as conjugative transposons. According to our knowledge only Izdebski et al. [27] showed the data concerning analysis

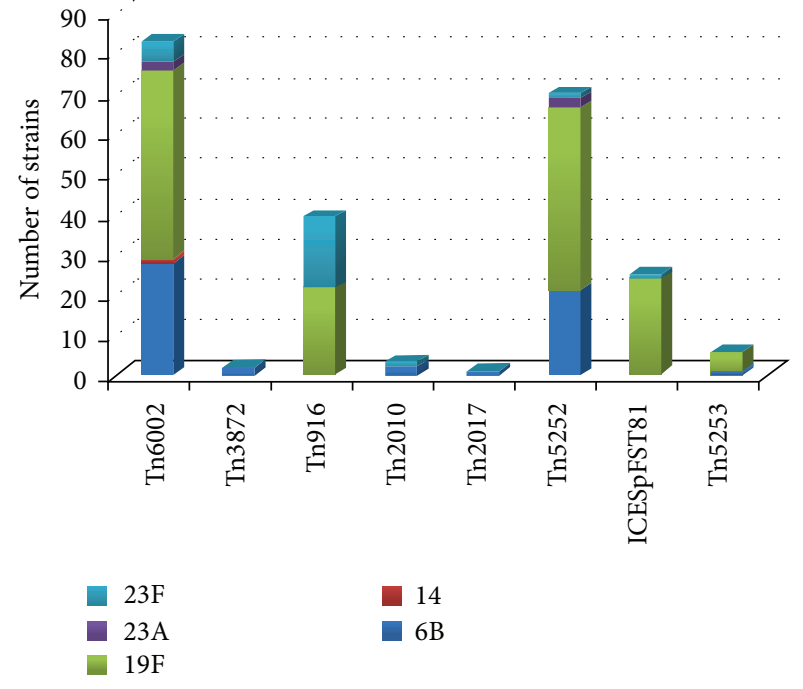

FIGURE 1: Transposon distribution among pneumococcal serotype of 138 S. pneumoniae nasopharyngeal isolates from healthy young children.

of tet(M)-carrying mobile elements among clinical isolates obtained from respiratory tract infections in Poland. In our study, we assessed distribution of resistance genes as well as presumable conjugative transposons in 138 resistant or multiresistant nasopharyngeal strains of $S$. pneumoniae obtained from healthy preschool children attending day care centres.

Macrolide and tetracycline resistance of pneumococci has increased in European countries, for example, Italy, France, and Spain, as well as in North America [28]. Poland belongs to a part of Europe with a high level of antibiotic consumption and above $20 \%$ rate of tetracycline and macrolide resistance among the pneumococcal isolates [29]. Resistance to macrolides associated with $M_{L} S_{B}$ phenotype is predominant in most European countries, whereas the $M$ phenotype predominates in North America, England, and Germany [30]. Our study confirmed that macrolide-resistant pneumococci in Poland are associated mainly with the $\mathrm{MLS}_{\mathrm{B}}$ phenotype, confirmed by the presence of erm(B) gene in the tested strains, as previously reported [27]. None of the tested strains possessed $\mathrm{M}$ phenotype as well as mef gene as a sole determinant of erythromycin resistance. Previous studies by Izdebski et al. [27] revealed among clinical pneumococcal strains in Poland only 4.7\% macrolide-resistant strains which possessed $m e f(\mathrm{E})$ instead of erm(B).

A worldwide emergence of pneumococci harboring both $\operatorname{erm}(\mathrm{B})$ and $m e f(\mathrm{E})$ genes, with the global prevalence of $16.4 \%$ among macrolide-resistant isolates, has been described [31]. The recent data from China have reported dramatically high proportion (62.9\%) of pneumococcal isolates with both $\operatorname{erm}(\mathrm{B})$ and $m e f A / E$ genes [32]. In the present study, we found only $8.1 \%$ macrolide-resistant isolates that harboured both genes and they were observed in 6B serotype, mostly.

The analysis of the mobile elements presented in this paper revealed their remarkable diversity in the population studied. Presence of Tn916 which is the prototype of the 
TABLE 2: Antibiotic resistance and transposon genes identified among 138 S. pneumoniae nasopharyngeal isolates from healthy young children.

\begin{tabular}{|c|c|c|c|c|c|}
\hline \multirow[b]{2}{*}{$\begin{array}{l}\text { Serotype (number } \\
\text { of strains) }\end{array}$} & \multirow[b]{2}{*}{ Resistance pattern } & \multicolumn{2}{|c|}{ Genes detected by PCR } & \multicolumn{2}{|c|}{ Presumptive transposons } \\
\hline & & Resistance genes & Transposon genes & $\begin{array}{c}\text { Tn916 family } \\
\text { element }\end{array}$ & Tn5252-like element \\
\hline $23 \mathrm{~F}(16)$ & $\mathrm{Te}$ & $\operatorname{tet}(\mathrm{M})$ & int/xis916 & $\operatorname{Tn} 916$ & \\
\hline $19 \mathrm{~F}(22), 23 \mathrm{~F}(1)$ & $\mathrm{TeC}$ & tet $(\mathrm{M}), c_{\mathrm{pC}}{ }_{\mathrm{pC} 94}$ & int/xis916, intICE & $\operatorname{Tn} 916$ & \\
\hline $\begin{array}{l}6 \mathrm{~B}(10), 14(1), 19 \mathrm{~F} \\
(2), 23 \mathrm{~F}(4)\end{array}$ & ECcTe & $\operatorname{tet}(\mathrm{M}), \operatorname{erm}(\mathrm{B})$ & int/xis 916 & $\operatorname{Tn} 6002$ & ICESp23FST81-like \\
\hline $6 \mathrm{~B}(2), 23 \mathrm{~F}(1)$ & ECcTe & $\operatorname{tet}(\mathrm{M}), \operatorname{erm}(\mathrm{B}), \operatorname{mef}(\mathrm{E})$ & int/xis 916 & $\operatorname{Tn} 2010$ & \\
\hline $6 \mathrm{~B}(1)$ & ECcTe & $\operatorname{tet}(\mathrm{M}), \operatorname{erm}(\mathrm{B}), \operatorname{mef}(\mathrm{E})$ & int/xis916, tnpA/tnpR & $\operatorname{Tn} 2017$ & \\
\hline $\begin{array}{l}\text { 6B (18), 19F (43), } \\
23 \mathrm{~A}(2), 23 \mathrm{~F}(1)\end{array}$ & ECcTeC & $\operatorname{tet}(\mathrm{M}), \operatorname{erm}(\mathrm{B})$, cat $_{\mathrm{pC} 194}$ & int/xis916, int/xis $\operatorname{Tn} 5252$ & $\operatorname{Tn} 6002$ & $\operatorname{Tn} 5252$ \\
\hline $6 \mathrm{~B}(1), 19 \mathrm{~F}(5)$ & ECcTeC & $\operatorname{tet}(\mathrm{M}), \operatorname{erm}(\mathrm{B})$, cat $_{\mathrm{pC} 194}$ & $\begin{array}{l}\text { int/xis } 916, \text { int } / x i s \operatorname{Tn} 5252, \\
\text { jun } \operatorname{Tn} 5253\end{array}$ & $\operatorname{Tn} 6002$ & Tn5253-like \\
\hline $6 \mathrm{~B}(1), 19 \mathrm{~F}(3)$ & ECcTeC & $\begin{array}{l}\text { tet }(\mathrm{M}), \operatorname{erm}(\mathrm{B}), \operatorname{mef}(\mathrm{E}) \text {, } \\
\operatorname{cat}_{\mathrm{pC} 194}\end{array}$ & int/xis916, int/xisTn5252 & $\operatorname{Tn} 2010$ & $\operatorname{Tn} 5252$ \\
\hline $6 \mathrm{~B}(2)$ & ECcTeC & $\operatorname{tet}(\mathrm{M}), \operatorname{erm}(\mathrm{B}), \operatorname{cat}_{\mathrm{pC} 194}$ & $\begin{array}{l}\text { int } / x i s 916, \operatorname{tn} p \mathrm{~A} / \operatorname{tn} p \mathrm{R} \\
\text { int/xis } \operatorname{Tn} 5252\end{array}$ & $\operatorname{Tn} 3872$ & $\operatorname{Tn} 5252$ \\
\hline $19 \mathrm{~F}(2)$ & ECcTeC & $\operatorname{tet}(\mathrm{M}), \operatorname{erm}(\mathrm{B})$, cat $_{\mathrm{pC} 194}$ & int/xis916, intICE & $\operatorname{Tn} 6002$ & ICESp23FST81-like \\
\hline
\end{tabular}

E: erythromycin, Cc: clindamycin, Te: tetracycline, and C: chloramphenicol.

Tn916 family was observed in all tetracycline-resistant but macrolide- and chloramphenicol-susceptible strains with $23 \mathrm{~F}$ serotype, comprising $11.6 \%$ of tested strains. The number of such strains was much lower than that described previously$38.8 \%$ [27].

There are some geographical differences in the prevalence and spread of transposons carried erm(B) gene in pneumococci. In Italy and Spain, the most frequently reported transposons in S. pneumoniae are Tn6002 and Tn3872, whereas in Japan Tn917 was found to be the most common [14, 23, 24, 33]. Tn 3872 is a composite, mobile element resulting from the insertion of the erm-containing Tn917 transposon into $\operatorname{Tn} 916$ [8, 23]. Our study showed that Tn6002 was more common among the erythromycin-resistant isolates, which accounts for $83.8 \%$ and Tn3872-related elements were found in only 3 of erm(B)-carrying $S$. pneumoniae strains with $6 \mathrm{~B}$ serotype $(3 \%)$, including one of them which is likely to possess larger mobile element, Tn2017. A study performed in China in 2010 on 135 macrolide-resistant pneumococci from nasal swabs of children revealed the high prevalence of Tn6002-like elements (56.3\% of isolates) and Tn3872 (5.2\%) [34]. This observation is comparable to other authors' data $[14,23,33]$.

Kanamycin resistance is related to $\operatorname{Tn} 1545$, a Tn916 family element that acquired erm(B) and aph3'III genes. A low prevalence of kanamycin resistance detected among the erythromycin- and tetracycline-resistant pneumococci was observed by other authors $[8,14,27,34]$ while our data showed lack of aph3-III gene among the studied strains. Besides, in the present study there were no isolates possessing all genetic markers pointed to the presence of $\operatorname{Tn} 1545 / \operatorname{Tn} 6003$ element.

Among the macrolide-resistant mef(E)-carrying strains, the presence of genetic element carrying a MEGA element such as Tn2009, Tn2010, and Tn2017 would be expected
$[13,15]$. In this study, strains harbouring both mef(E) and erm(B) genes were detected; therefore the $\operatorname{Tn} 2010$ and $\operatorname{Tn} 2017$ transposons were suggested. Tn2010 was first detected in an Italian isolate [13] and then it was detected in the different studies with various frequencies $(2-28.9 \%)[14,34]$. The presence of $\operatorname{Tn} 2010$ in $72.2 \%$ of macrolide-resistant isolates from China was detected and the CC271 strains carrying the Tn2010 element expressing the high-level resistance to erythromycin were predominant in China [35].

All of the studied isolates which were resistant to chloramphenicol proved to harbour cat $_{\mathrm{C} 194}$ carried by Tn5253like element. These composite elements demonstrate substantial heterogeneity results from at least two levels of variability, in the Tn5252-like and in the Tn916-like transposons [26]. Two variants of the Tn5252-related transposon were distinguished depending on the presence of the int5252 and xis5252

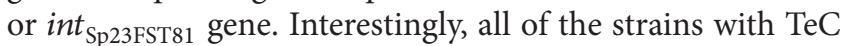
resistance pattern and $19 \mathrm{~F}$ or $23 \mathrm{~F}$ serotype possessed elements positive for int $t_{\mathrm{Sp23FST} 81}$. This can be the proof of clonal spreading of these strains in children population. The presence of Tn5253-family and ICESp23FST81-family elements has been investigated in clinical isolates of $S$. pneumoniae and proven to be frequent, especially among multidrug resistant strains $[26,36]$.

Both Tn916 and another transposon from a number of Tn916 family pneumococcal relatives carrying a variety of insertion containing erythromycin resistance genes such as $\operatorname{erm}(\mathrm{B})$ or $m e f(\mathrm{E})$ or both in addition to the tet(M) tetracycline resistance determinant typical for the family [24, 37] can be found as independent elements and inserted into Tn5252-related transposons to form a Tn5253-like composite element [26]. It is possible that in most of studied strains, tet $(\mathrm{M})$ and $\mathrm{erm}(\mathrm{B})$ reside in Tn916-like elements, whereas cat gene was located in separate transposons. Out of 101 chloramphenicol-resistant strains, in which cat-containing 
transposon was detected, only in 5.9\% isolates an association with tet $(\mathrm{M})$ was confirmed, as in the case of Tn5253. However, the possibility that other Tn916-like elements were inserted into Tn5252-related transposon could not be excluded and additional experiments should be conducted with suitable primer pairs to seek a linkage with the associated Tn916-like transposon.

The 138 resistant/multiresistant S. pneumoniae strains tested were distributed into 5 serotypes and 37 BOX PCR types [19]. These findings, in addition to the genotypic differences found in this study, indicate that the studied strains were partially related to the place of isolation (day care center), regarding isolates with $19 \mathrm{~F} \mathrm{ECcTeC} \mathrm{phenotype}$ especially. This suggests a spread of resistance due to clonal dissemination mainly. Children in day care centres due to close contact with each other are more frequently at risk of respiratory tract infections and antimicrobial consumption. Their nasopharynx can be colonized by pneumococci and other types of bacteria for up to a few months facilitating transfer of genetic material between bacterial strains $[9,38]$. Children nasopharynx is therefore a likely place for antimicrobial resistance to emerge, and resistance rates can increase fast. The epidemiological relationship between strains colonizing healthy children and strains causing pneumococcal infections has been documented before, so surveillance studies of pneumococcal carriage allow monitoring strains circulating in community, including their antibiotic resistance.

\section{Conclusions}

The high prevalence of macrolide, tetracycline, and chloramphenicol resistance among $S$. pneumoniae strains was mainly due to clonal dissemination of multiresistant strains in the children populations. However, owing to phenotypic and genotypic differences observed in tested strains, horizontal spread of the Tn916 family of transposons, which can be found as independent elements as well as inserted into Tn5252-related transposons to form a Tn5253-like composite element, was also feasible.

\section{Conflict of Interests}

The authors declare that there is no conflict of interests regarding the publication of this paper.

\section{Acknowledgment}

The paper was developed using the equipment purchased within the agreement no. POPW.01.03.00-06-010/09-00, Operational Program Development of Eastern Poland 20072013, Priority Axis I, Modern Economy, Operations 1.3. Innovations Promotion.

\section{References}

[1] D. Bogaert, R. de Groot, and P. W. M. Hermans, "Streptococcus pneumoniae colonisation: the key to pneumococcal disease," Lancet Infectious Diseases, vol. 4, no. 3, pp. 144-154, 2004.
[2] N. Givon-Lavi, D. Fraser, N. Porat, and R. Dagan, "Spread of Streptococcus pneumoniae and antibiotic-resistant S. pneumoniae from day-care center attendees to their younger siblings," Journal of Infectious Diseases, vol. 186, no. 11, pp. 1608-1614, 2002.

[3] A. P. Roberts and P. Mullany, "Tn916-like genetic elements: a diverse group of modular mobile elements conferring antibiotic resistance," FEMS Microbiology Reviews, vol. 35, no. 5, pp. 856871, 2011.

[4] T. Shiojima, Y. Fujiki, H. Sagai, S. Iyobe, and A. Morikawa, "Prevalence of Streptococcus pneumoniae isolates bearing macrolide resistance genes in association with integrase genes of conjugative transposons in Japan," Clinical Microbiology and Infection, vol. 11, no. 10, pp. 808-813, 2005.

[5] M. P. Montanari, M. Mingoia, E. Giovanetti, and P. E. Varaldo, "Differentiation of resistance phenotypes among erythromycinresistant pneumococci," Journal of Clinical Microbiology, vol. 39, no. 4, pp. 1311-1315, 2001.

[6] A. Brenciani, A. Bacciaglia, M. Vecchi, L. A. Vitali, P. E. Varaldo, and E. Giovanetti, "Genetic elements carrying erm(B) in Streptococcus pyogenes and association with tet $(\mathrm{M})$ tetracycline resistance gene," Antimicrobial Agents and Chemotherapy, vol. 51, no. 4, pp. 1209-1216, 2007.

[7] P. Courvalin and C. Carlier, "Tn1545: a conjugative shuttle transposon," Molecular and General Genetics, vol. 206, no. 2, pp. 259-264, 1987.

[8] L. K. McDougal, F. C. Tenover, L. N. Lee et al., "Detection of Tn917-like sequences within a Tn916-like conjugative transposon (Tn3872) in erythromycin-resistant isolates of Streptococcus pneumoniae," Antimicrobial Agents and Chemotherapy, vol. 42, no. 9, pp. 2312-2318, 1998.

[9] F. Santoro, M. E. Vianna, and A. P. Roberts, "Variationon a theme; an overview of the Tn916/Tn1545 family of mobile genetic elements in the oral and nasopharyngeal streptococci," Frontiers in Microbiology, vol. 5, article 535, 2014.

[10] M. Santagati, F. Iannelli, C. Cascone et al., "The novel conjugative transposon Tn1207.3 carries the macrolide efflux gene mef(A) in Streptococcus pyogenes," Microbial Drug Resistance, vol. 9, no. 3, pp. 243-247, 2003.

[11] K. Gay and D. S. Stephens, "Structure and dissemination of a chromosomal insertion element encoding macrolide efflux in Streptococcus pneumoniae," Journal of Infectious Diseases, vol. 184, no. 1, pp. 56-65, 2001.

[12] M. Del Grosso, J. G. E. Northwood, D. J. Farrell, and A. Pantosti, "The macrolide resistance genes $\operatorname{erm}(\mathrm{B})$ and $m e f(\mathrm{E})$ are carried by $\operatorname{Tn} 2010$ in dual-gene Streptococcus pneumoniae isolates belonging to clonal complex CC271," Antimicrobial Agents and Chemotherapy, vol. 51, no. 11, pp. 4184-4186, 2007.

[13] M. Del Grosso, R. Camilli, F. Iannelli, G. Pozzi, and A. Pantosti, "The mef(E)-carrying genetic element (mega) of Streptococcus pneumoniae: insertion sites and association with other genetic elements," Antimicrobial Agents and Chemotherapy, vol. 50, no. 10, pp. 3361-3366, 2006.

[14] L. Calatayud, C. Ardanuy, F. Tubau et al., "Serotype and genotype replacement among macrolide-resistant invasive pneumococci in adults: mechanisms of resistance and association with different transposons," Journal of Clinical Microbiology, vol. 48, no. 4, pp. 1310-1316, 2010.

[15] M. del Grosso, F. Iannelli, C. Messina et al., "Macrolide efflux genes $m e f(\mathrm{~A})$ and $m e f(\mathrm{E})$ are carried by different genetic elements in Streptococcus pneumoniae," Journal of Clinical Microbiology, vol. 40, no. 3, pp. 774-778, 2002. 
[16] P. Ayoubi, A. O. Kilic, and M. N. Vijayakumar, “Tn5253, the pneumococcal $\Omega$ (cat tet) BM6001 element, is a composite structure of two conjugative transposons, Tn5251 and Tn5252," Journal of Bacteriology, vol. 173, no. 5, pp. 1617-1622, 1991.

[17] M. N. Vijayakumar, S. D. Priebe, and W. R. Guild, "Structure of a conjugative element in Streptococcus pneumoniae," Journal of Bacteriology, vol. 166, no. 3, pp. 978-984, 1986.

[18] R. Provvedi, R. Manganelli, and G. Pozzi, "Characterization of conjugative transposon Tn5251 of Streptococcus pneumoniae," FEMS Microbiology Letters, vol. 135, no. 2-3, pp. 231-236, 1996.

[19] I. Korona-Glowniak and A. Malm, "Characteristics of Streptococcus pneumoniae strains colonizing upper respiratory tract of healthy preschool children in Poland," The Scientific World Journal, vol. 2012, Article ID 732901, 10 pages, 2012.

[20] J. Sutcliffe, T. Grebe, A. Tait-Kamradt, and L. Wondrack, "Detection of erythromycin-resistant determinants by PCR," Antimicrobial Agents and Chemotherapy, vol. 40, no. 11, pp. 2562-2566, 1996.

[21] M. P. Montanari, M. Mingoia, I. Cochetti, and P. E. Varaldo, "Phenotypes and genotypes of erythromycin-resistant pneumococci in Italy," Journal of Clinical Microbiology, vol. 41, no. 1, pp. 428-431, 2003.

[22] C. A. Widdowson, P. V. Adrian, and K. P. Klugman, "Acquisition of chloramphenicol resistance by the linearization and integration of the entire staphylococcal plasmid pC194 into the chromosome of Streptococcus pneumoniae," Antimicrobial Agents and Chemotherapy, vol. 44, no. 2, pp. 393-395, 2000.

[23] I. Cochetti, E. Tili, M. Mingoia, P. E. Varaldo, and M. P. Montanari, "erm(B)-carrying elements in tetracycline-resistant pneumococci and correspondence between Tn1545 and Tn6003," Antimicrobial Agents and Chemotherapy, vol. 52, no. 4, pp. 12851290, 2008.

[24] I. Cochetti, E. Tili, M. Vecchi et al., "New Tn916-related elements causing erm(B)-mediated erythromycin resistance in tetracycline-susceptible pneumococci," Journal of Antimicrobial Chemotherapy, vol. 60, no. 1, pp. 127-131, 2007.

[25] C. Poyart, G. Quesne, P. Acar, P. Berche, and P. Trieu-Cuot, "Characterization of the Tn916-like transposon Tn3872 in a strain of Abiotrophia defectiva (Streptococcus defectivus) causing sequential episodes of endocarditis in a child," Antimicrobial Agents and Chemotherapy, vol. 44, no. 3, pp. 790-793, 2000.

[26] M. Mingoia, E. Tili, E. Manso, P. E. Varaldo, and M. P. Montanari, "Heterogeneity of Tn5253-like composite elements in clinical Streptococcus pneumoniae isolates," Antimicrobial Agents and Chemotherapy, vol. 55, no. 4, pp. 1453-1459, 2011.

[27] R. Izdebski, E. Sadowy, J. Fiett, P. Grzesiowski, M. Gniadkowski, and W. Hryniewicz, "Clonal diversity and resistance mechanisms in tetracycline-nonsusceptible Streptococcus pneumoniae isolates in Poland," Antimicrobial Agents and Chemotherapy, vol. 51, no. 4, pp. 1155-1163, 2007.

[28] M. R. Jacobs, D. Felmingham, P. C. Appelbaum et al., "The Alexander project 1998-2000: susceptibility of pathogens isolated from community-acquired respiratory tract infection to commonly used antimicrobial agents," Journal of Antimicrobial Chemotherapy, vol. 52, no. 2, pp. 229-246, 2003.

[29] S. Riedel, S. E. Beekmann, K. P. Heilmann et al., "Antimicrobial use in Europe and antimicrobial resistance in Streptococcus pneumoniae," European Journal of Clinical Microbiology and Infectious Diseases, vol. 26, no. 7, pp. 485-490, 2007.

[30] R. R. Reinert, A. Ringelstein, M. van der Linden, M. Y. Cil, A. Al-Lahham, and F.-J. Schmitz, "Molecular epidemiology of macrolide-resistant Streptococcus pneumoniae isolates in Europe," Journal of Clinical Microbiology, vol. 43, no. 3, pp. 12941300, 2005.

[31] D. J. Farrell, S. G. Jenkins, S. D. Brown, M. Patel, B. S. Lavin, and K. P. Klugman, "Emergence and spread of Streptococcus pneumoniae with erm(B) and mef(A) resistance," Emerging Infectious Diseases, vol. 11, no. 6, pp. 851-858, 2005.

[32] Q. Geng, T. Zhang, Y. Ding et al., "Molecular characterization and antimicrobial susceptibility of Streptococcus pneumoniae isolated from children hospitalized with respiratory infections in Suzhou, China," PLoS ONE, vol. 9, no. 4, Article ID e93752, 2014.

[33] N. Okitsu, S. Kaieda, H. Yano et al., "Characterization of ermB gene transposition by Tn1545 and Tn917 in macrolideresistant Streptococcus pneumoniae isolates," Journal of Clinical Microbiology, vol. 43, no. 1, pp. 168-173, 2005.

[34] L. Zhou, X. Ma, W. Gao et al., "Molecular characteristics of erythromycin-resistant Streptococcus pneumoniae from pediatric patients younger than five years in Beijing, 2010," BMC Microbiology, vol. 12, article 228, 2012.

[35] Y. Li, H. Tomita, Y. Lv et al., "Molecular characterization of erm(B)- and mef(E)-mediated erythromycin-resistant Streptococcus pneumoniae in China and complete DNA sequence of Tn2010," Journal of Applied Microbiology, vol. 110, no. 1, pp. 254265, 2011.

[36] S. K. Henderson-Begg, A. P. Roberts, and L. M. C. Hall, "Diversity of putative Tn5253-like elements in Streptococcus pneumoniae," International Journal of Antimicrobial Agents, vol. 33, no. 4, pp. 364-367, 2009.

[37] A. P. Roberts and P. Mullany, "A modular master on the move: the Tn916 family of mobile genetic elements," Trends in Microbiology, vol. 17, no. 6, pp. 251-258, 2009.

[38] R. Sá-Leão, S. Nunes, A. Brito-Avô et al., "High rates of transmission of and colonization by Streptococcus pneumoniae and Haemophilus influenzae within a day care center revealed in a longitudinal study," Journal of Clinical Microbiology, vol. 46, no. 1, pp. 225-234, 2008. 

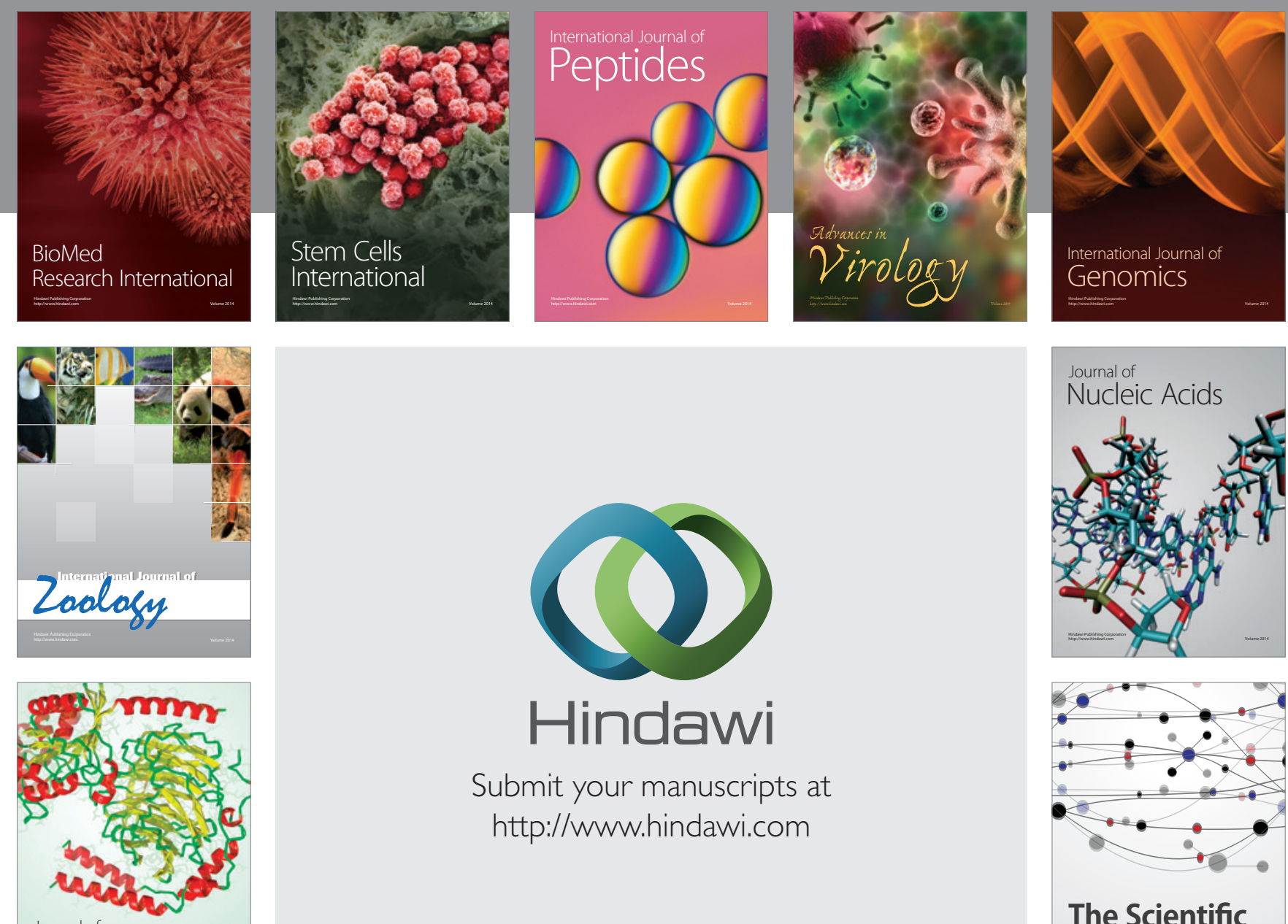

Submit your manuscripts at

http://www.hindawi.com

Journal of
Signal Transduction
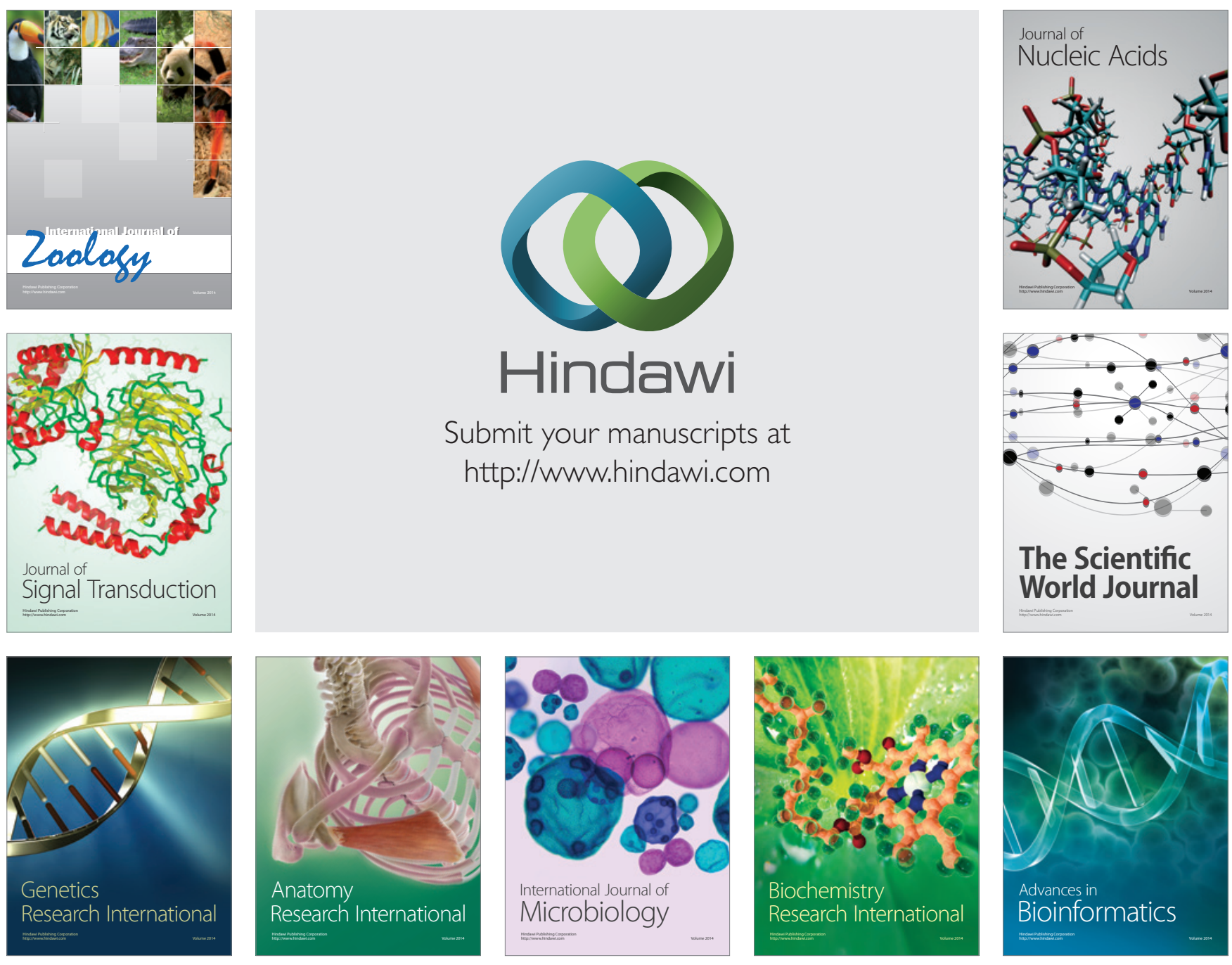

The Scientific World Journal
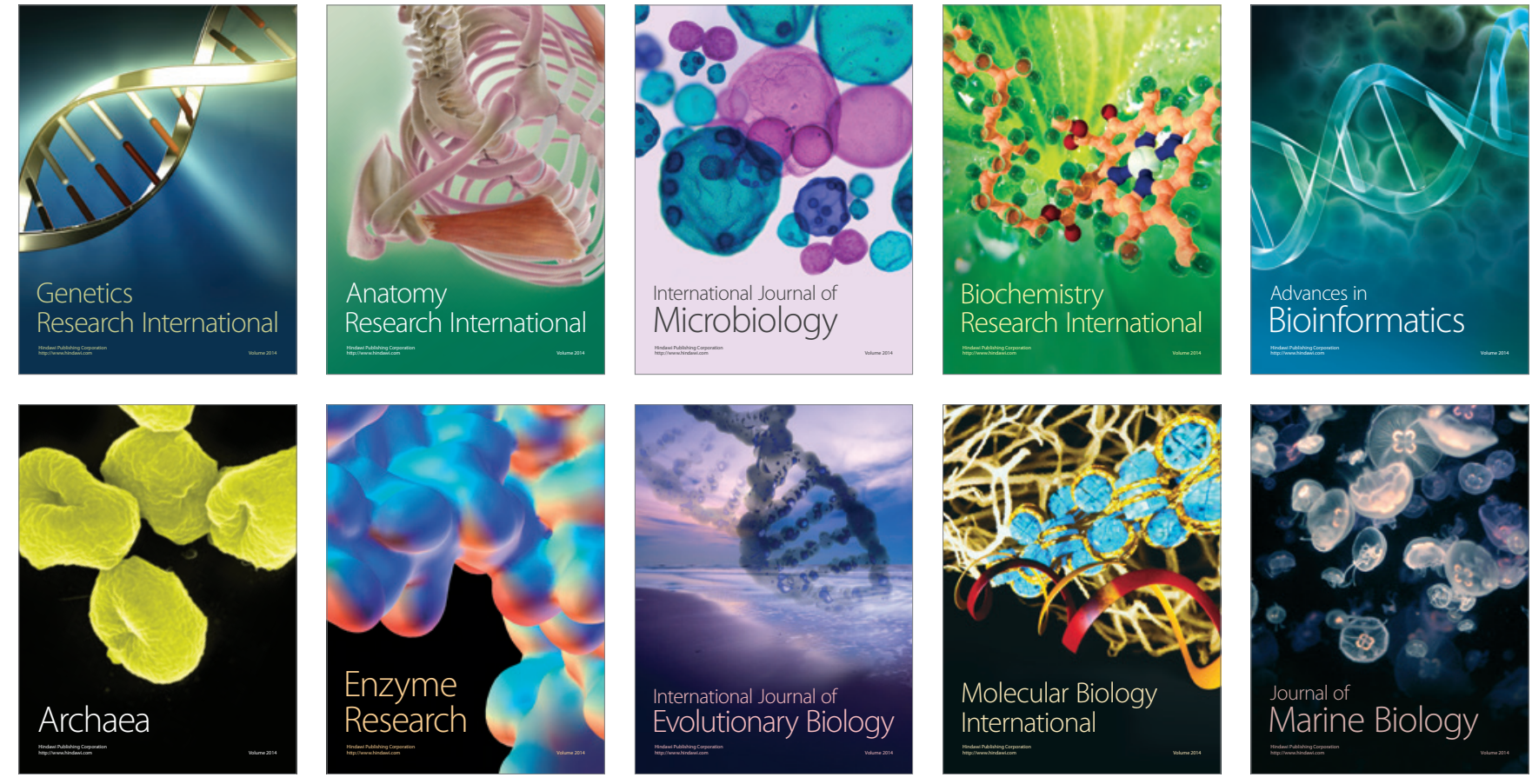